\title{
KT Corp của Hàn Quốc đẩy mạnh công nghệ blockchain để bảo vệ môi trường
}

- sciencevietnam $\leftleftarrows$ Cuộc sống (1) September 06, 2021

ENHANCED BY Google

SSHPA (09-06-2021) - Mới đây, trang tin Finbold cho biết tập đoàn viễn thông lớn của Hàn Quốc là KT Corp đang thúc đẩy kế hoạch phát triển một nền tảng tài liệu điện tử dựa trên công nghệ blockchain [1]. Mục tiêu lớn của dự án này chính là làm giảm lượng khí thải carbon toàn cầu.

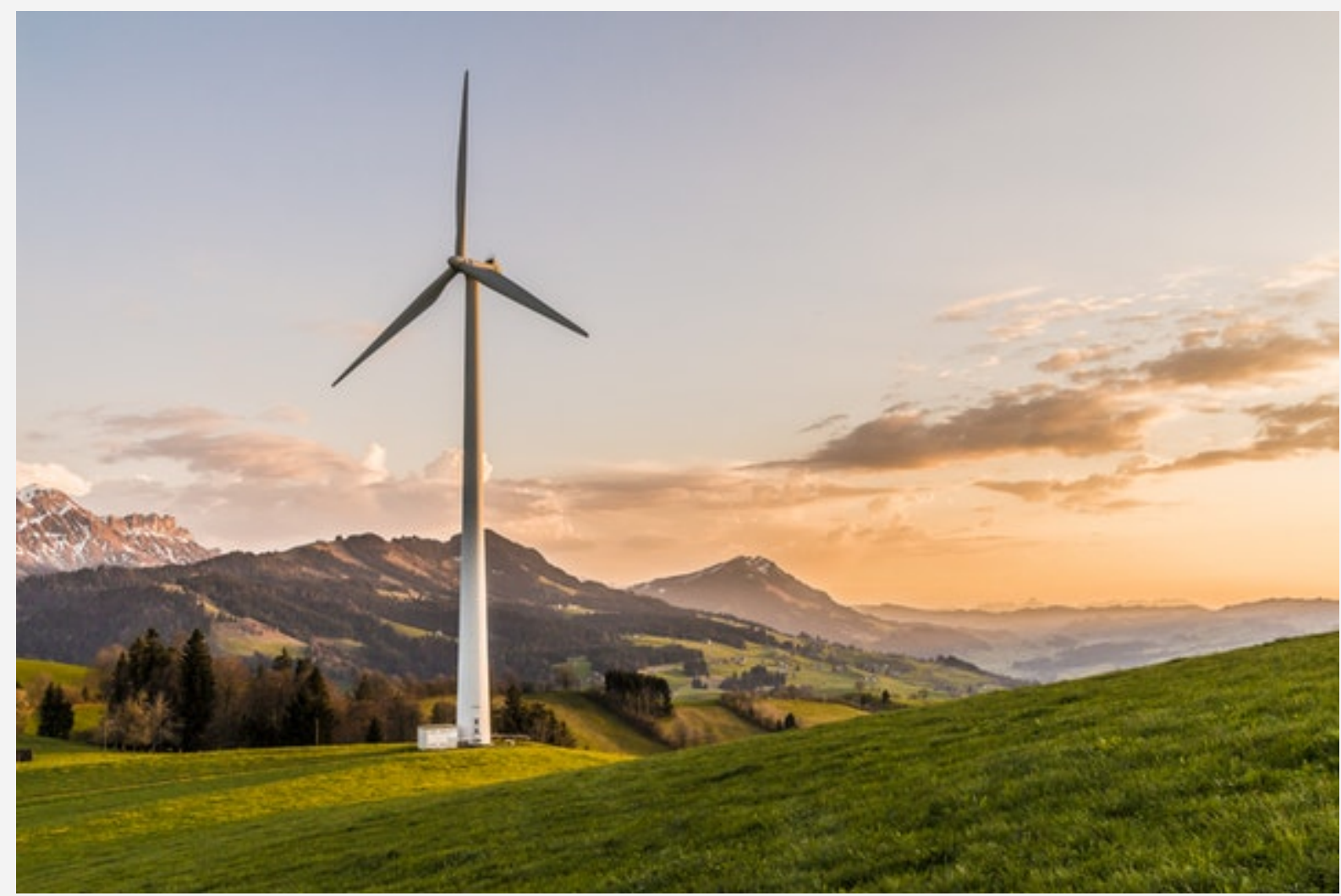

Dự án này hướng tới mục tiêu sẽ chuyển đổi 4,5 tỷ tài liệu giấy sang định dạng số trong một năm. Ước tính, con số này sẽ giúp giảm 130 tỷ tấn carbon/năm.

Kể từ khi ra đời tới nay, công nghệ blockchain được coi là một giải pháp để góp phần giảm lượng khí thải toàn cầu [1]. Tuy nhiên, khi các dàn máy đào tiền ảo vẫn đang chạy hết công suất [2], vấn đề về khí thải carbon do công nghệ sản sinh ra cũng cần được nhà nhà đầu tư, doanh nghiệp lưu tâm [3-5].

Con người đang sở hữu nhiều công nghệ tiềm năng để giải quyết vấn đề quan trọng của thế giới. Mặc dù vậy, giá trị của các phát kiến khoa học này sẽ lớn tới mức nào thì vẫn chưa thể có câu trả lời trọn vẹn [6]. 
Tài liệu tham khảo:

[1] Baltrusaitis J. (2021). South Korea's telecom giant to launch blockchain-based e-doc platform to curb carbon emissions. Finbold. URL: https://finbold.com/southkoreas-telecom-giant-to-launch-blockchain-based-e-doc-platform-to-curb-carbonemissions/

[2] Baltrusaitis J. (2021). Demand for mining rigs triples in Vietnam as Bitcoin surges past $\$ 51,000$. Finbold. URL: https://finbold.com/demand-for-mining-rigs-triples-invietnam/

[3] Schröder P, Sharpe O. (2021). Bitcoin's carbon footprint could crush its potential. Chatham House. URL: https://www.chathamhouse.org/2021/05/bitcoins-carbonfootprint-could-crush-its-potential

[4] Vuong QH., et al. (2021). Identifying the moral-practical gaps in corporate social responsibility missions of Vietnamese firms: an event-based analysis of sustainability feasibility. Corporate Social Responsibility and Environmental Management, 28(1), 30-41.

[5] Vuong QH. (2021). The semiconducting principle of monetary and environmental values exchange. Economics and Business Letters, 10(3), 1-9.

[6] Vuong QH. (2018). The (ir)rational consideration of the cost of science in transition economies. Nature Human Behaviour, 2(1), 5

(1) Last modified: 9/6/2021 5:21 PM Views: 0

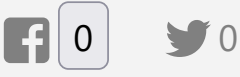

Bài liên quan:

- Chúng ta cần biện pháp nhanh, mạnh để có thể ổn định khí hậu toàn cầu

- Trong Rừng Dẻ Gai, nhà văn Nguyễn Thị Ngọc Tú và bài báo quốc tế

- Bảo vệ môi trường: Không có cơ chế để "đổi chác các bù"

- Cheo cheo lưng bạc Việt Nam được giới khoa học tái phát hiện

- The Guardian thay đổi ngôn từ trong truyền thông môi trường để chuyểnbiến nhận thức

Ý kiến bạn đọc (0):

Comment

Gửi bình luận

(c) 2018 - 2021 EASE Vietnam SciComm System. All rights reserved. Powered by Vuong \& Associates. 